\title{
Pharmaceuticalization and Biomedicalization: An Examination of Problems Relating to Depression in Japan
}

\author{
Shoko Okudaa
}

\begin{abstract}
The growing number of people suffering from depression has become a social problem in Japan. The problems associated with depression in Japan have been influenced by the pharmaceuticalization of mental health. Since selective serotonin reuptake inhibitors were introduced to Japan's pharmaceutical market in 1999, demand for anti-depressant medications has rapidly expanded. It seems likely then that the efforts of pharmaceutical companies, as part of their marketing strategies, to increase people's awareness of mental illness have led people who are not actually depressed to have medical consultations and drug treatments for it. This phenomenon is known as "disease mongering" and has been reported on. Problems exist from the medical perspective also and include the following: expansion of the diagnostic criteria for depression as formulated in the American Psychiatric Association's Diagnostic and Statistical Manual of Mental Disorders; treatments that rely heavily on drugs; and biomedicalization. Another reason for the increase in medical consultations is the declining function of communal bodies. This has resulted in individuals struggling psychologically, for example, with anxiety, worry, and depression. In summary, this sociological research analyzed the problems of depression in Japan and revealed how the pharmaceuticalization of mental health accelerates the individualization of social problem.
\end{abstract}

\section{Keywords}

Depression, pharmaceuticalization, biomedicalization, illness awareness campaigns, disease mongering

Depression has become more widespread in Japanese society over the last 10 to 20 years, and the growing number of people with depression in Japan today is becoming a social problem. Over the years, depression has changed from an unusual psychological disorder affecting only a few people into a "common, everyday" mental disorder that can affect anyone (Nomura 2008).

Situated in the background of Japan's problems with depression has been a marked shift to biomedical and pharmaceutical treatment models, which is referred to in this paper as the processes of "biomedicalization" and "pharmaceuticalization" of mental health and illness. As a consequence of these trends, an inordinate number of illness awareness campaigns have arisen as part of promotional efforts by pharmaceutical companies to increase sales of prescription drugs. These campaigns appear to have had a significant impact on people's awareness and behaviors surrounding depression (Tomitaka 2009).

aKeio University, Japan

\section{Correspondent Author:}

Shoko Okuda, Tsukuda 2-1-2-1007, Chuo-ku, Tokyo 104-0051, Japan

E-mail: okusho-sho@nifty.com 
The goal of the present study was to examine the issue of depression in Japan from a sociological perspective. While drawing on international comparisons, it is hypothesized that depression-oriented illness awareness campaigns by pharmaceutical companies have convinced people to seek medical treatment from medical institutions and that, moreover, this is a form of what might be called "disease mongering" - a tactic by which people have been convinced to seek medical treatment involving prescribed drug treatment when they do not actually suffer from depression.

The prescription drugs for treating depression that this research is concerned with are principally selective serotonin reuptake inhibitors (SSRIs) and other new anti-depressants. Compared with the situation in Europe and the USA, in Japan, there is a bias toward using pharmacotherapeutic methods for treating depression. In addition, the expanded diagnostic scope for depression, which has come about through the use of operational diagnostic criteria based on the Diagnostic and Statistical Manual of Mental Disorders (DSM) formulated by the American Psychiatric Association (APA), constitutes a problem on the part of the medical community itself. The discussion in this paper will therefore also consider the perspective that these additional factors could also be contributing to any supposed disease mongering by pharmaceutical companies through their illness awareness campaigns. In addition, with reference to what Beck (1992) has pointed to as the ongoing acceleration of the "individualization of social problems", we also reflect on the relationship of individualization to people's treatment-seeking behaviors.

\section{METHODS}

The methodological analysis undertaken in this study considers mutual relationships and commonalities identified through a close examination of survey findings from public and private Japanese research institutions. Specifically, the large-scale Ministry of Health, Labour, and Welfare (MHLW) Patient Survey is drawn upon. This survey is an important resource for understanding treatment trends (e.g., how many patients are admitted to which departments) as well as how these are changing over time. Also considered are survey findings by professional research organizations in the private sector that look for depression-related leave-taking and absenteeism in corporations and survey findings by private research firms that follow trends in the market for new anti-depressants, particularly SSRIs, as well as changes in the number of depression-related compensation claims and approvals by workers, which has been seen to impact heavily on corporate losses. Sources produced by UK Government agencies and the APA's "Depression Guidelines" are also drawn upon in order to compare the way depression is treated in the UK and USA with the way it is treated in Japan, where there has been a bias toward pharmacotherapy in the context of the biomedicalization and pharmaceuticalization of mental health and illness. Finally, the APA's DSM as the basis of current operational diagnosis, and the history of DSM, are discussed in the Japanese context.

\section{RESEARCH RESULTS}

First, the current situation with regard to depression in Japan will be explained from a statistical and investigative perspective. In this regard, there are three main points: (1) an increased number of patients with depression (i.e., seeking treatment for it); (2) an increase in depression-related absenteeism and leaves of absence; and (3) an increase in depression-related compensation claims and approvals by workers. All of these trends began to increase sharply around 1999.

As a background to these increases, according to the MHLW Patient Survey, which is conducted once every three years ${ }^{1}$, a total of 958,000 people suffered from "mood disorders" (i.e., depression and related 
disorders $)^{2}$ in 2011. While this number represents a reduction of more than 80,000 over the $1,041,000$ people who suffered mood disorders in the 2008 survey, it remains a significant long-term increase when compared with the total of 433,000 people from the 1996 survey, representing a $220 \%$ rise over the intervening 15 years (see Figure 1).

Moreover, an increasing number of workers have been taking leave from the workplace, claiming to be suffering from depression. According to a 2010 survey conducted by the Institute of Labor Administration (targeting 3,917 companies, mainly publicly listed corporations), it was found that the number of companies reporting the presence of employees who had been absent or had taken leave for more than one month due to depression and related mental health disorders accounted for $63.5 \%$ of the total; this proportion rose to as much as $97.5 \%$ when the survey target was further restricted to large corporations with 1,000 or more employees. In a 2012 survey by the Japan Productivity Center's Mental Health Research Institute (targeting 2,140 publicly listed corporations), the percentage of firms reporting a rise in employees suffering from depression and other mental disorders over the three years leading up to the survey was $37.6 \%$. Although individual companies are introducing new measures to address workplace mental health with each passing year, including early detection initiatives like the establishment of consultation services, the provision of access to industrial psychiatrists, and improvements to the leave-taking and return-to-work policies associated with depression and similar mental disorders, the sense that such measures had been insufficiently effective was also reported by nearly half (47.2\%) of the companies surveyed.

In conjunction with the increase among workers complaining of depression in the workplace, there has also been a steady rise in the number of claims, both filed and approved, for workers' compensation benefits owing to depression and related mental disorders. In the MHLW Survey of Worker Compensation Payouts for Brain, Heart, and Mental Disorders, a record high of 1,409 mental health-related claims for workers' compensation were filed in the 2013 fiscal year. Despite the fact that only 436 of these claims were approved, representing a reduction over the previous year for the first time since 2009, when viewed over the longer term, the number of approvals is steadily increasing. Whereas a mere 42 claims were filed in 1998, of which only four were approved, these numbers suddenly jumped to 212 claims and 36 approvals in 2000, since which time the pace of increase has not stopped (see Figure 2).

This rise in absenteeism and leave-taking by employees suffering from depression represents a major burden for corporations, who are facing lost productivity and increased stress on the part of supervisors and HR and health management personnel, the loss of talented personnel, increased risk of workers' compensation claims being approved due to violations of the duty to provide a safe working environment, and a deterioration in company morale and brand image. Furthermore, this situation has given rise to significant losses not only for individual companies, but for society as a whole. According to 2009 statistics compiled by the National Institute of Population and Social Security Research, a total of 45.6 billion yen was paid out in workers' compensation benefits to people suffering from depression, with a further 18.7 billion in unemployment benefits to those who lost their jobs due to depression, 304.6 billion in depression-related welfare benefits, and 297.1 billion in depression-related medical care costs.

So, what is in the background to the problem of depression in Japan? The key points here are the following: (1) the inordinate number of illness awareness campaign activities by pharmaceutical companies seeking to expand the new anti-depressant market, and the possibility that these activities have 


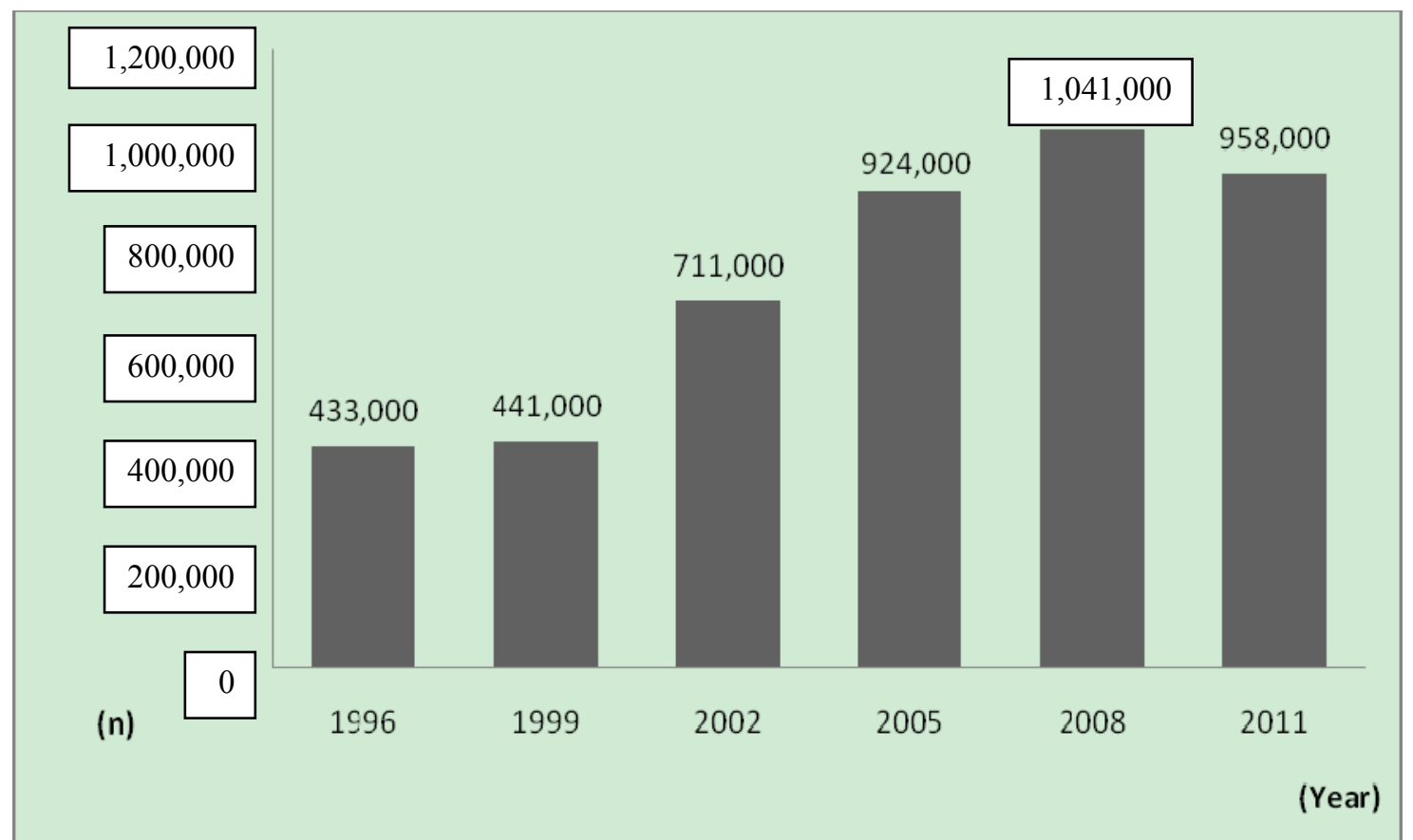

Figure 1. Trends in the Number of Patients Receiving Inpatient or Outpatient Care for Depression in Japan (Based on MHLW, Patient Survey).

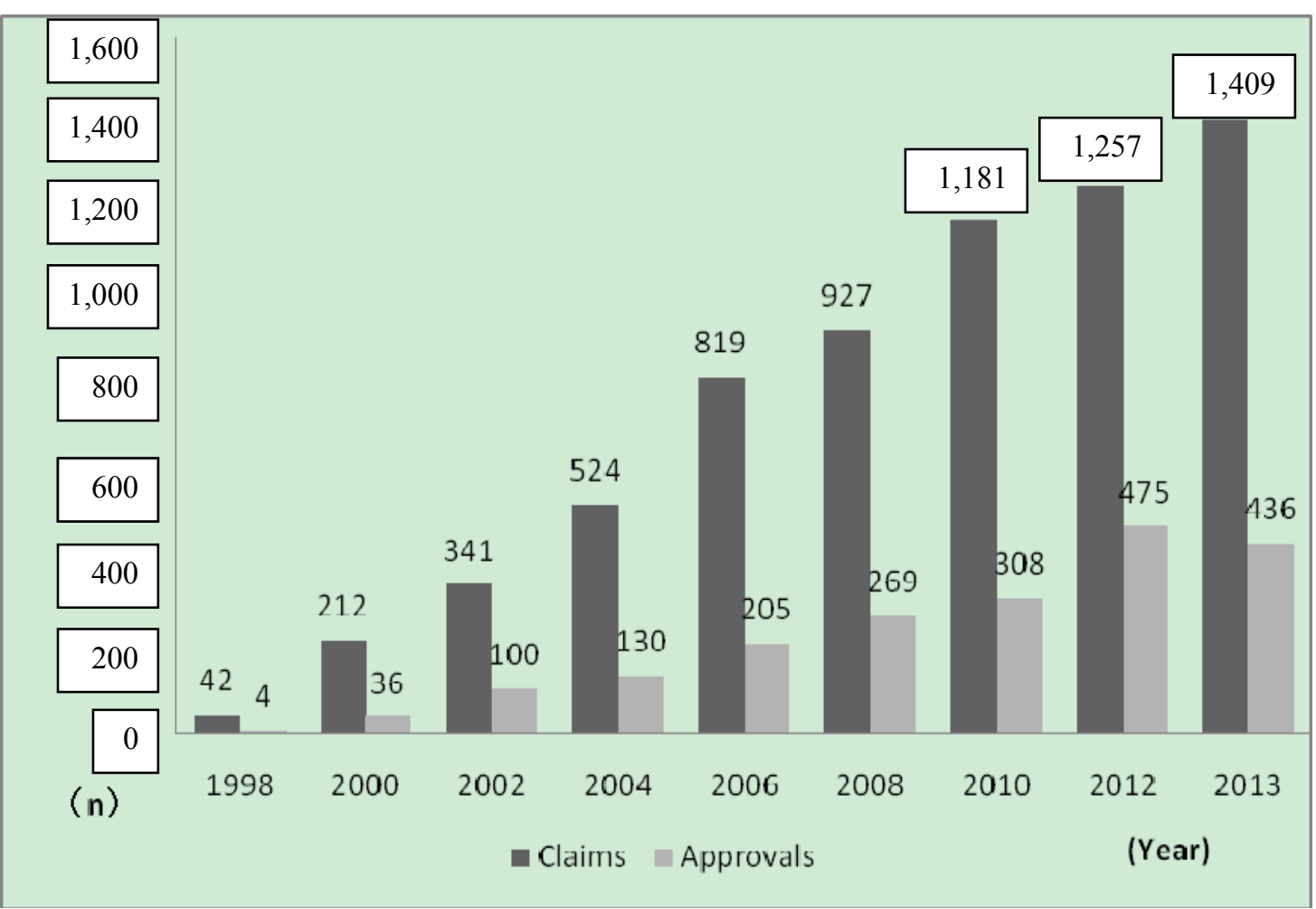

Figure 2. Trends in Workers' Compensation Claims and Approvals for (Depression-Related) Mental Disorders (Based on MHLW, Survey of Worker Compensation Payouts for Brain, Heart, and Mental Disorders). 
paved the way for disease mongering; (2) against a backdrop of biomedicalization, the bias toward pharmacotherapeutic treatment methods for depression; and (3) the expanded diagnostic scope for depression due to the adoption of operational diagnostic criteria used in the West.

Prior to the entry of new anti-depressants such as SSRIs onto the domestic market in 1999, the size of the anti-depressant drug market in Japan had remained on the order of 17 billion yen. However, with the release of SSRIs, the market immediately began to grow rapidly, and by 2012, it had reached 137.7 billion yen, a more than eightfold expansion over the dozen years since their appearance on the market. This increase in anti-depressant sales, which is to say the increase in the number of prescriptions, is thought to be commensurate with the increase in the number of patients diagnosed with depression (see Figure 3).

SSRIs came on to the Japanese market in 1999. In other words, this suggests that the factors characterizing the present situation with regard to depression in Japan that were alluded to earlier - that is, the increase among patients (diagnosed) with depression, the increase among employees who have been absent or taken leave from work due to depression, and the increase in workers' compensation claims, filed and approved, relating to depression - also began to develop all at once in the same year.

Underlying this trend has been the influence of marketing strategies, including promotional campaigns and an inordinate focus on disease awareness activities, intended as a means to increase drug sales for these new anti-depressants. Specifically, such means have included television advertisements, online promotions, sponsored depression-related lecture events oriented to the general public (in more than a few such cases with the involvement of members of the psychiatric community), and the publication of special feature articles on the subject of depression in advertising-supported medical journals and magazines for the general public. These various initiatives have inculcated the notion that depression is no longer a mental disorder afflicting only a few individuals, but rather an illness affecting a broad range of people. As a result, from around 2000, the public perception began to take root in Japan of depression as a "common, everyday" form of mental illness, a perception reinforced by popular catchphrases like "kokoro no kaze" that characterize depression as the "common cold of the soul".

What becomes problematic here is the criticism of "disease mongering"; namely, that pharmaceutical companies, by carrying out their numerous illness awareness activities, were increasing drug sales unnecessarily with the result that they were "pushing" treatment in a way that actually "manufactured" illness. In their 2005 book Selling Sickness, Ray Moynihan and Alan Cassels discuss depression and other illnesses likely to be the target of such "disease mongering"3. They fiercely criticize the methods employed by the pharmaceutical industry - promoting drugs in advertising campaigns that exaggerate the actual number of patients and redefine "risk of illness" as "illness"- as amounting to the manufacture of new illnesses for the express purpose of expanding the market, and all the while in the guise of "illness awareness".

In Japan, as well, there has been some indication of how the rapidly increasing number of patients, suffering from mild depression in particular, has been the result of illness awareness activities that have been a part of pharmaceutical companies' marketing strategies (Tomitaka 2009). In other words, this points to the possibility that people who are not actually suffering from depression have been seeking and receiving pharmaceutical treatment from medical institutions.

Here, against the backdrop of its biomedicalization, let us touch on the bias in Japan toward the 


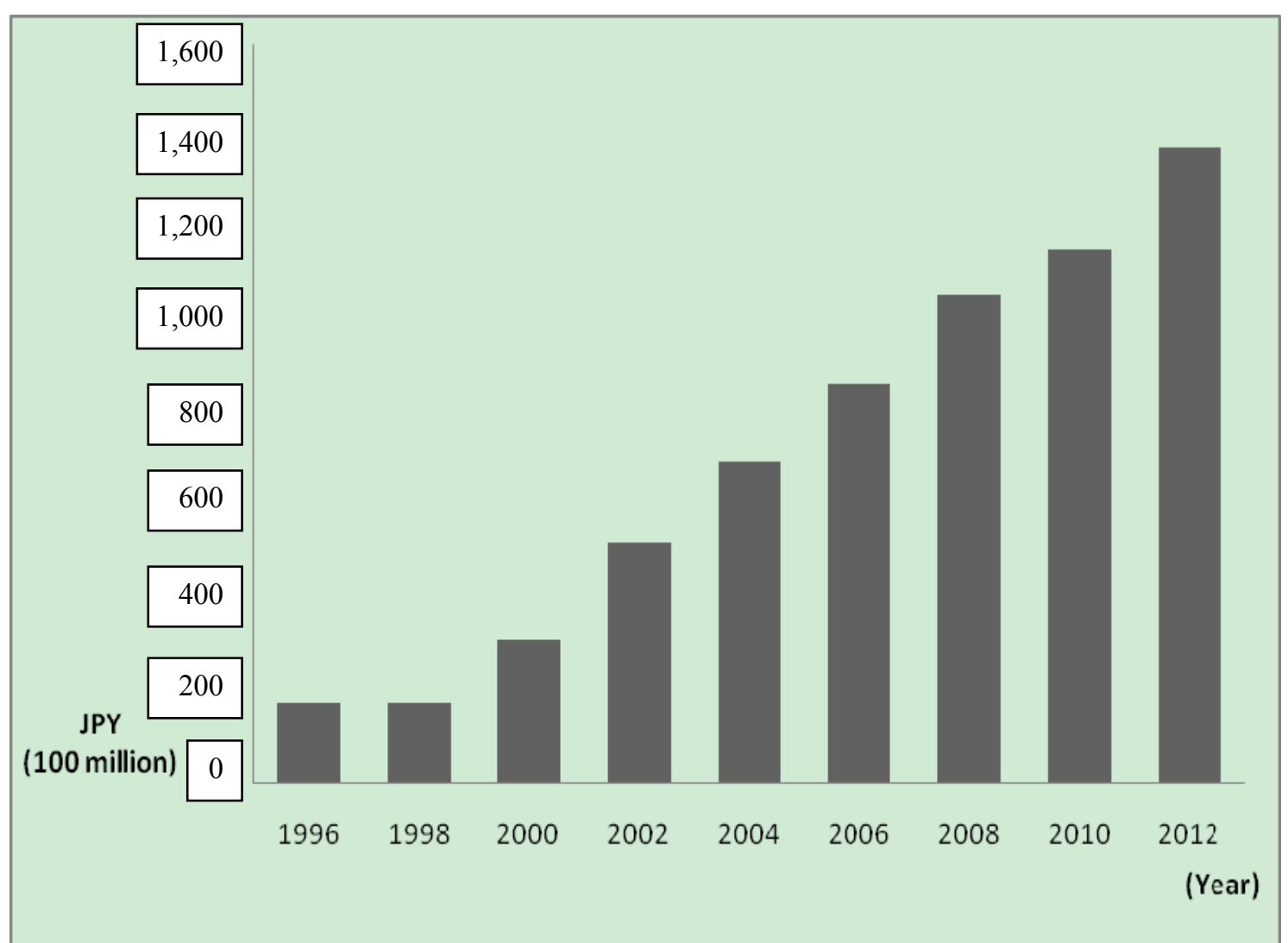

Figure 3. Trends in Japan's Antidepressant Marketplace (Based on Fuji Keizai, Prescription Drug Databook).

pharmacotherapeutic treatment of depression in international comparison with Western countries. Actually, the phenomenon whereby the number of patients suffering from depression began to increase rapidly following the release of new anti-depressants also occurred in a similar manner in the West when SSRIs became available more than 10 years prior to their release in Japan. This took place from the late 1980s until the early 1990s when SSRIs appeared on the market in countries like the USA, Canada, the UK, France, and Australia. On average, the situation in each of these countries saw the number of patients suffering from depression roughly double during the first five or six years that SSRIs were available, which is consistent with the experience in Japan over the corresponding period (McManus et al. 2000;
Nakagawa et al. 2007).

Nevertheless, there is a major difference in that unlike in the USA and UK where, upon careful consideration of the balance between the effectiveness of anti-depressants and adverse side effects such as nausea and constipation, the use of anti-depressants is restricted in cases of mild depression in respective drug treatment guidelines, in Japan pharmaceutical treatment has been carried out regardless of the severity of a patient's depression. For example, the depression treatment guidelines released by NICE (the National Institute for Health and Care Excellence), the UK Government agency tasked with determining treatment policy stipulate that "Anti-depressants are not recommended for the initial treatment of mild depression, because the risk/benefit ratio is poor" 
(Depression: Management of Depression in Primary and Secondary Care, NICE 2004). In the USA, as well, the APA's treatment policy, as defined in its guidelines for the treatment of depression, states that "Anti-depressant medications should be provided for moderate to severe major depressive disorder" (Practice Guideline for the Treatment for the Treatment of Patients With Major Depressive Disorder, APA 2000).

Behind these differing responses by Japan and the West is the fact that, in Japan, even before the phenomenon of the increase in the number of patients suffering from depression that accompanied the release of SSRIs onto the market, that is, the increase in the number of people seeking treatment for depression (and especially the increase in mild depression), it had been unusual for patients with mild depression to seek treatment at medical institutions. In addition, there are also indications that because the majority of such patients suffered from moderate to severe depression, the task of formulating treatment policies in accordance with the severity of depression had been neglected.

Let us move now to a discussion of the expanded diagnostic scope for depression due to the more widespread use of operational diagnostic criteria based on the APA's DSM. The criteria employed by physicians in Japan today for diagnosing depression are substantially based on the 2013 edition of the Diagnostic and Statistical Manual of Mental Disorders, 5th Edition (DSM-V) published by the APA. While the text has undergone repeated revisions since the first edition of the DSM was released in 1952, it has moved from a classification based on conventional etiologies to the adoption of operational diagnostic criteria focusing on presenting symptoms starting with the publication of DSM-III in 1980 [and continued thereafter in DSM-III-R (1987), DSM-IV (1994), DSM-IV-TR (2000), up to DSM-V]. In Japan, the adoption of diagnostic criteria based on the DSM started in the 1980s with the publication of DSM-III, and by the 1990s had spread to psychiatric practice in clinical settings.

Nevertheless, in Japan, there are indications that the elimination of diagnostic methods based on conventional etiologies and the adoption of these operational diagnostic criteria with their emphasis on presenting symptoms led to the expansion of the diagnostic range for depression. In his 2008 book about The Truth of Depression (Utsubyō no shinjitsu), Sōichirō Nomura, after criticizing current conditions that facilitate blanket diagnoses of depression by physicians, points to the problem, stating that "(the practice of writing) medical certificates for depression has taken on a life of its own, while an increasing number of people are taking extended periods of leave from their companies despite the fact that they actually suffer from weakness of personality or neuroses other than depression". He also goes on to mention the problem of how the expanded diagnostic range for depression is interpreted even more widely in society at large, to the point that incidences of "self-diagnosed" depression have appeared (i.e., people claim to be depressed when in fact they are not).

\section{DISCUSSION}

Against the background of problems described thus far-pharmaceutical companies, (clinical) psychiatric care, and psychiatric medicine-let us turn now to consider what kinds of factors have motivated people's treatment-seeking behavior.

First of all, we will consider the problems that Japan is now facing with depression in light of the theory of individualization advanced by Ulrich Beck (1992). Beck's theory was formulated with reference to the welfare state of the contemporary West Germany in which he was writing. In the case of Japan, however, welfare has been largely reliant on company-based employee welfare and mutual aid 
inside the family. For this reason, social integration in Japan has not followed a European-style welfare state model of integration, but rather followed a corporate societal model. Herein lies the unique character of individualization in the Japanese context. Individualization in Japan began with the decline of communal bodies such as local communities and corporations, which had until then played the role of mitigating risk. In today's more advanced age, even the family, which had helped to complement these communal bodies, has been exposed to the danger of collapse, which has led to the rise of the "individualized family". These transformations in Japanese society have resulted in the individualization of social problems; that is, the situation whereby social problems come to affect individuals directly, a problem that has now become truly serious for Japan as well. In other words, in an age and society where social problems are each being transformed into mental dispositions at the individual level (e.g., problems like anxiety, dysphoria, and depression), it seems all the more likely that pharmaceuticalization has been encouraging people to become aware of depression on their own, to self-diagnose, and then to seek treatment at medical institutions.

While Beck has also referred to "the current revival of interest in psychology" (Beck 1992: 100), the concept of "psychologized society" has also been expounded by Aiko Kashimura (2003) and Tamaki Saitō (2009) as a problem for contemporary Japan. This psychologized society refers to a social situation where a wide variety of social phenomena and mental health issues come to be described in the language of psychology and psychiatric care, with words like "stress" and "trauma". With the loss of the world made up of communal interpersonal distances like family and local community—or in other words, with the advance of individualization - the medium that has come to fill that gap is the "psyche" (kokoro) referred to by psychology and psychiatric medicine. Such people are likely to be easily swayed by illness awareness campaigns staged by pharmaceutical companies, and it is conceivable that having sought treatment from a medical institution, they will start being treated by pharmacotherapeutic methods whether they suffer only from mild depression or even are not ill at all.

\section{CONCLUSIONS}

Finally, to sum up the discussion, having reflected on pharmaceuticalization while referring to the case of the issue of depression in Japan, there appears to be the following three problematic areas: (1) pharmaceutical companies (i.e., their illness awareness campaigns that are intended to increase the market for new anti-depressants); (2) (clinical) psychiatric treatment (i.e., a bias toward the pharmacotherapeutic treatment of depression without reference to severity); and (3) the field of psychiatric medicine (i.e., the expanded diagnostic scope for diagnosis of depression due to the increased adoption of operational diagnostic criteria). Pharmaceuticalization has been further accelerated by the individualization of social problems, and appears to have resulted in the production of social inequality between those who continue to persevere in their work even in the face of difficulty and mental or physical discomfort and those who take extended leave from their companies, writing off personal weakness or even slight mental or physical discomfort to illness - or, understood more broadly, in the production of social inequality between those who struggle to actively confront the harsh reality with which they are faced, and those who only pretend to struggle, even as they turn away and flee from the difficulties confronting them.

As challenges for future research, further implications of pharmaceuticalization in Japan should be considered, including the comparison of depression with other illnesses, the interaction between awareness and behavior among additional people, and its impact on society. 


\section{Acknowledgements}

The author is deeply grateful to Dr. Ichiro Innami, Keio University, for advice and fruitful discussions.

\section{Notes}

1. These surveys indicate the number of patients admitted for inpatient or outpatient medical care in Japanese medical institutions at the time of the survey.

2. There is no direct category for mental illness in the Japanese Ministry of Health, Labour and Welfare's Patient Survey for depression (various years). Instead, there is a "mood disorders" category, comprised mainly of depression. According to DSM-V, the international mental illness categorization/diagnostic standard published by the American Psychiatric Association (2013), mood disorders include disorders other than depression, such as bipolar disorder. However, because the majority of cases in the Ministry's Patient Survey were depressive patients, this "mood disorders" category is normally used in academic papers and government and local authority reports when referring to the problem of depression in Japan.

3. In addition to depression, Moynihan and Cassels also cite diseases such as high blood pressure, menopause, and osteoporosis as examples of diseases likely to be targeted for disease mongering.

\section{References}

American Psychiatric Association (APA). 2013. Quick Reference to the Diagnostic Criteria From DSM-V. Arlington, USA: American Psychiatric Association.

Beck, U. 1992. Risk Society: Toward a New Modernity. Thousand Oaks, USA: Sage Publications Ltd.

Breggin, P. and G. Breggin. 1994. Talking Back to Prozac: What Doctors Aren't Telling You About Today's Most Controversial Drug. New York, USA: St. Martin's Press.

Freidson, E. 1970. Professional Dominance: The Social Structure of Medical Care. Palo Alto, USA: Atherton Press, Inc.

Fuji Keizai. 1996. Prescription Drugs Databook. Tokyo, Japan: Fuji Keizai.

—. 2000. Prescription Drugs Databook. Tokyo, Japan: Fuji Keizai.

—. 2002. Prescription Drugs Databook. Tokyo, Japan: Fuji Keizai.

—. 2004. Prescription Drugs Databook. Tokyo, Japan: Fuji Keizai.

—. 2006. Prescription Drugs Databook. Tokyo, Japan: Fuji
Keizai.

—. 2008. Prescription Drugs Databook. Tokyo, Japan: Fuji Keizai.

—. 2010. Prescription Drugs Databook. Tokyo, Japan: Fuji Keizai.

—. 2012. Prescription Drugs Databook. Tokyo, Japan: Fuji Keizai.

Healy, D. 2003. Let Them Eat Prozac: The Unhealthy Relationship Between the Pharmaceutical Industry and Depression. Toronto, Canada: James Lorimer \& Company Ltd., Publishers.

Institute of Labor Administration, Japan. 2010. Mental Health in Corporations: Situation and Countermeasures. Japan.

Japan Productivity Center. 2012. Corporate Survey on Mental Health Activities. Tokyo, Japan: Japan Productivity Center.

Japanese Ministry of Health, Labour and Welfare. 1996. Patient Survey. Tokyo: Japanese Ministry of Health, Labour and Welfare.

- 1998. Survey of Worker Compensation Payouts for Brain, Heart, and Mental Disorders. Tokyo: Japanese Ministry of Health, Labour and Welfare.

- 1999. Patient Survey. Tokyo: Japan Ministry of Health, Labour and Welfare.

- 2000. Survey of Worker Compensation Payouts for Brain, Heart, and Mental Disorders. Tokyo: Japanese Ministry of Health, Labour and Welfare.

_. 2002a. Patient Survey. Tokyo: Japan Ministry of Health, Labour and Welfare.

- 2002b. Survey of Worker Compensation Payouts for Brain, Heart, and Mental Disorders. Tokyo: Japanese Ministry of Health, Labour and Welfare.

- 2004. Survey of Worker Compensation Payouts for Brain, Heart, and Mental Disorders. Tokyo: Japanese Ministry of Health, Labour and Welfare.

_ 2005. Patient Survey. Tokyo: Japan Ministry of Health, Labour and Welfare.

- 2008a. Patient Survey. Tokyo: Japan Ministry of Health, Labour and Welfare.

- 2008b. Survey of Worker Compensation Payouts for Brain, Heart, and Mental Disorders. Tokyo: Japanese Ministry of Health, Labour and Welfare.

- 2010. Survey of Worker Compensation Payouts for Brain, Heart, and Mental Disorders. Tokyo: Japanese Ministry of Health, Labour and Welfare.

—. 2011. Patient Survey. Tokyo: Japan Ministry of Health, Labour and Welfare.

2012. Survey of Worker Compensation Payouts for Brain, Heart, and Mental Disorders. Tokyo: Japanese Ministry of Health, Labour and Welfare.

Kasahara, Y., I. Yamashita, and T. Hirose. 1993. Depression (Mood Disorders). Tokyo, Japan: Shinryō Shinsha. 
Kashimura, A. 2003. Clinical Sociology of the "Psychologized Society”. Yokohama, Japan: Seori Shobō.

Kazamatsuri, H. 2008. A History of Japanese Modern Mental Health Drug Therapy. Tokyo, Japan: Arc Media.

Kuroda, K., ed. 1995. The Sociology of Modern Medicine: Current State and Issues Facing Japan. Kyoto, Japan: Sekai Shisoōsha.

McManus, P., A. Mant, P. B. Mitchell, W. S. Montgomery, J. Marley, and M. E. Auland. 2000. "Recent Trends in the Use of Anti-Depressant Drugs in Australia, 1990-1998." The Medical Journal of Australia 173(9):458-461.

Moynihan, R. and A. Cassels. 2005. Selling Sickness: How the World's Biggest Pharmaceutical Companies Are Turning Us All Into Patients. Sydney, Australia: Allen and Unwin Australia.

Nakagawa, A., M. F. Grunebaum, S. P. Ellis, M. A. Oquendo, H. Kashima, R. D. Gibbons, and J. J. Mann. 2007. "Association of Suicide and Anti-Depressant Prescription Rates in Japan, 1999-2003." The Journal of Clinical Psychiatry 68(6):908-916.

Nakayasu, N. 2002. "Considering the Concept of Depression: The 'Crime' of the Major Depression (DSM-V) Concept." Psychiatric Treatment 27(8):991-998.

National Institute of Population and Social Security Research. 2009. Societal Loss Due to Suicide/Depression. Tokyo, Japan.

Nomura, S. 2008. The Truth of Depression. Tokyo, Japan: Nippon Hyōronsha.
Parsons, T. 1964. Social Structure and Personality. New York, USA: Free Press.

Saitō, T. 2009. Psychologized Society: Cure "Trauma" or the "Brain"? Kawade Shobō Shinsha.

Shibuya, H. 1998a. "Major Depressive Disorder.” Pp. 183-210 in Encyclopedia of Clinical Psychiatry 4: Mood Disorders, edited by H. Tetsuya and O. Akihiko. Tokyo, Japan: Nakayama Shoten.

. 1998b. "History/Concept/Classification." Pp. 3-9 in Encyclopedia of Clinical Psychiatry 4: Mood Disorders, edited by H. Tetsuya and O. Akihiko. Tokyo, Japan: Nakayama Shoten.

Tajima, O. 2006. Mental Health's Quiet Revolution: The Good and Bad of Psychotropic Drugs. Tokyo, Japan: Bensei Publishing.

Tomitaka, S. 2009. Why Are There More Depressed People? Tokyo, Japan: Gentōsha Runessansu.

Utsumi, T. 1999. "Treatment History of Depression." Pp. 397-409 in Encyclopedia of Clinical Psychiatry S1: History of Mental Health, edited by M. Masaaki and H. Genjirō. Tokyo, Japan: Nakayama Shoten.

\section{Bio}

Shoko Okuda, Ph.D. candidate, Graduate School of Media and Governance, Keio University, Japan; research fields: social psychology, medical sociology, and media study. 